\title{
On the semantic history of selected terms of endearment
}

\author{
Agnieszka Grząśko \\ Rzeszów University, Poland
}

\begin{abstract}
The present paper attempts to discuss the semantic history of a handful of terms of endearment (aka pet names, sweet talk, affectionate talk, soft words, terms of affection or sweet words) and the role of the cognitive mechanisms in the changes of their meaning. We focus the reader's attention on a few lexical items which represent such mechanisms as foodsemy (e.g. honey, sugar), which seems to be one of the most prolific ones, plantosemy (pumpkin) or zoosemy (pet). Furthermore, we trace the semantic development of terms which from the beginning of their existence have been employed as pet names (sweetheart), words which are no longer endearments, because they underwent the process of meaning amelioration or pejoration (mopsy, bully) and last but not least - nouns whose semantic shift is based on the pattern (POSITIVE) EMOTIONS $\rightarrow$ ENDEARMENTS (joy).
\end{abstract}

Keywords: endearment, amelioration, pejoration, zoosemy, foodsemy, plantosemy

\section{Introduction}

At first sight, the world of interpersonal and intimate language that people, especially romantic partners, may develop just for themselves might seem to be infantile and deprived of creativity. By and large, we revolve around diminutive forms of words connected with pet names, various animals, children or sweetness. Depending on the context, terms of endearment serve to convey two main functions: on the one hand in some areas they are part and parcel of everyday speech and one may find it unusual if they are left out, because they express emotions and strengthen ties; on the other hand such words may be perceived as disparaging or condescending, as they may imply incompetence, foolishness or weakness of the addressee.

The aim of the following paper is to gain an insight into both the semantic history of a few selected pet names and the role of cognitive mechanisms in the changes of their meaning. In what follows we define the term endearment, subdivide endearments into smaller sets and 
discuss the history of a handful of such terms which represent the mechanisms of foodsemy ${ }^{1}$ (honey, sugar, tart), zoosemy ${ }^{2}$ (pet) or plantosemy ${ }^{3}$ (pumpkin). We also trace the history of words which from the very beginning of their existence have been used as endearments (sweetheart), lexical items which used to be endearments, but underwent the process of meaning pejoration (bully) or amelioration (mopsy), and terms whose semantic shift is based on the pattern (POSITIVE) EMOTIONS $\rightarrow$ ENDEARMENTS (joy).

\section{Definition and division of endearments}

The term endearment may be defined as a form of address; it is a word or phrase employed either to address or describe a person, animal or inanimate object for which the speaker feels affection. It is fitting to add that endearments are coterminous with forms such as sweet words, pet names, sweet talk, affectionate talk, soft words or terms of affection (Afful and Nartey 2013). According to the Oxford English Dictionary (henceforth the OED), the word in question was first documented in English in the second half of the $17^{\text {th }}$ century in the sense the action of endearing or the fact of being endeared; something that endears, that excites or increases affection' (1663 The Object of all this Care, this Indeerment and joy, is the Ark of God.).

Terms of endearment are words which in their human-specific sense may not bear even faint resemblance to the original meaning, for example when calling your partner mushroom, dove or sugar-pie. A number of pet names derive from each other, take sweet-cheeks, sweetheart, sweetie, sweetie-pie, sweetkins, sweets or babe, baby, babykins, baby-girl, baby-face, but there is also an enormous number of terms that bear no etymological resemblance, for example apricot or button (http://www.yaelf.com/toe.shtml). The vast majority of endearments are employed with reference to people with whom we are on familiar terms; by and large, this intimate language concerns lovers, partners, close friends and family members. Note that frequently people use pet names only when they are alone and some words are only employed in specific situations (http://blog.maart.com/en/content/language-loveinternational-and-polish-terms-endearment). Interestingly, not all terms of endearment are of romantic nature, a few such lexical items fail to be associated with any kind of eroticism or affection at all (e.g. prawn). ${ }^{4}$

1 Foodsemy is nicknaming from foodstuffs which means that names of various foodstuffs may be used to denote human qualities.

2 Zoosemy is understood in the literature (Rayevska 1979: 165) as nicknaming from animals which means that names of animals are often used to denote human qualities.

3 Plantosemy is understood as nicknaming from plants which means that names of plants are employed to denote human qualities.

4 Following the $O E D$, despite the fact that prawn, when used with reference to persons, has been used as a term of contempt since the $19^{\text {th }}$ century (1845 You never saw such a human Prawn as he looked, in your life.), there is a single quotation suggesting that that the word could be used as an endearment (1895 I expect you're a saucy young prawn, Emma). 
Terms of endearment ${ }^{5}$ may be subdivided into smaller sets. The vast majority of the socalled 'sweet' words fit the mechanisms of animal metaphor known as zoosemy (e.g. chick, chuck, bunny, turtle, dove, lamb, duck, duckling, lambie, dove, kitten, mouse) and of foodsemy (e.g. honey, cupcake, honey pie, sugar, muffin, cookie, peach, sugar pie), which seem to be the most prolific ones. It is more than likely that a number of foodstuffs and animal terms have idiosyncratic or nonce usages than are attested in the OED (Crystal 2014). Crystal (2014) stresses that some pet names are affected by fashion, and various types of fish serve as an example of this thesis. Hence, individual cases extracted from the OED prove that whiting (1529 He callyth me his whytyng.) or sparling (1570 I wylbe bolde wyth my nowne darlyng, Cum now, a bas, my nowne proper sparlyng.) used to be terms of endearment, even though now such terms might seem disparaging. Therefore, the pattern FISH $\rightarrow$ ENDEARMENT may be said to be a less popular one.

One may find isolated cases of plantosemy (buttercup, pumpkin) and words which result from a semantic shift based on the pattern INANIMATE OBJECT $\rightarrow$ ENDEARMENT, or - to be more precise - TOY $\rightarrow$ ENDEARMENT (doll, baby doll). Interestingly enough, there are a handful of cases of royal terms (e.g. queen, princess, duchess) and sky-terms (e.g. star, sunshine, sun) which also function as popular pet names. At the same time, one may speak about a group of words which name objects belonging to the conceptual category of CHILD (baby, babe, baby-face, poppet, kiddo), which refer to both adults and children. It is worth noting that there are some lexical items which in the course of time underwent the semantic process of meaning shift and are no longer used as terms of endearment (bully, mopsy, jug, pug) (Kochman-Haładyj 2007).

\section{Methodological outline}

Generally speaking, the apparatus adopted for our scrutiny draws on elements of the cognitive framework. In this section, we shall briefly account for selected principles on which the analysis of endearments is based. Firstly, following Lakoff (1987) and Taylor (1995), the notion of 'conceptual category' is understood here as embodied in our conceptual systems, which grow out of bodily experience and make sense in terms of it; moreover, the core of our conceptual systems is directly grounded in perception, body movement, and experience of a physical and social character (Lakoff 1987:xiv). The particular interest of our analysis is the conceptual category ENDEARMENTS.

In turn, the notion of 'domains' has been used by both Langacker (1987) and Lakoff (1987) for the same construct, which may be labeled as a 'frame', 'scene' or 'schema'. Langacker (1987: 488) defines it as a coherent area of conceptualization relative to which semantic units may be characterized. To be more precise, the meaning of the semantic concept 'knuckle' is relative to 'finger' or 'hand', thus these two concepts constitute a domain for 'knuckle'. In other words, a conceptual domain is understood here as a set consisting of various attributive (or conceptual) values (or elements). Furthermore, these elements are specified for various locations within the attributive paths of conceptual domains.

5 Terms of endearment have been taken from the OED, Oxford Dictionary of Slang and The Random House Thesaurus of Slang. 
Following Schmid (2010: 119), the notion of 'entrenchment' is used to refer to the degree to which the formation and activation of a cognitive unit is routinized and automated. It is the relation of a lexical category to certain locations within the conceptual dimension of a given domain. Furthermore, the meaning of the analyzed words will be accounted for in terms of activation (aka highlighting) of conceptual elements. For some senses of a lexical item conceptual elements are rendered as being either foregrounded (more salient) or backgrounded (less important).

\section{The analysis of selected terms of endearment}

\section{BULLY}

Let us commence the analysis with the semantic development of the word bully, which is documented to have undergone the process of meaning shift at least twice. The noun was originally employed as a term of endearment, but at some point of its evolution it underwent the process of meaning pejoration and acquired negatively-loaded senses.

All the consulted lexicographic sources (the OED; Word Origins; A Concise Etymological Dictionary of Modern English and A Short Etymological Dictionary of Modern English) agree that the word is of obscure etymology, although - in all likelihood - it has its roots in Dutch boel 'lover (of either sex)' and 'brother'. The former sense of the word, which is also a term of endearment, may have originated as baby-talk. Following the $O E D$, the Dutch form comes from modern German buhle 'lover', earlier also 'friend, kinsman'.

According to the $O E D$, the historically primary sense of bully, which survived until the middle of $18^{\text {th }}$ century, may be defined as 'a term of endearment and familiarity'. At first, the word was applied to either sex as a synonym for sweetheart and darling. Hence, within the cognitively-couched model of semantic analysis employed, we may speak about activation of the conceptual value EPICENE presupposed for the attributive path of the domain of SEX.

Later - for some unknown reasons - the noun started to be applied to men exclusively, implying friendly admiration, a good friend and fine fellow. Following the $O E D$, the lexical item was frequently prefixed as a kind of title to the name or designation of the person addressed, for example in Shakespeare bully Bottom, bully knight, bully monster or bully doctor. Curiously, in Shakespeare's plays it occurs 19 times in total as an address form (Busse 2002).

It is fitting to add that the above-mentioned senses of the word are labeled here as both obscure and archaic. Cognitively speaking, the semantics of the noun may be said to have undergone a shift within the conceptual domain of SEX; we are dealing here with the transfer from the epicene sense 'sweetheart' to the male specific one, which may be accounted for in terms of activation of the conceptual value MALE and backgrounding of the value FEMALE.

The following OED historical contexts of use testify to the historically primary positively or neutrally-loaded senses of bully:

1538 Though she be sumwhat olde It is myne owne swete bullye My muskyne and my mullye.

1688 A Band of Bully Scholars, marching under ground with their Black-Bills.

1754 I haue promised to be with the sweet Bully early in the morning of her important day. 
The quotations in the OED range from 1538 to 1754, hence the lexical item had been used in its original sense for only 200 years before it fell into oblivion. As confirmed by Word Origins, the lexical item in question has undergone a decline in status. In the second half of the $17^{\text {th }}$ century the word pejorated to be used in the negatively-loaded sense 'a blustering gallant; a bravo, hector, or 'swash-buckler'; now, especially a tyrannical coward who makes himself a terror to the weak' (1688 A lady is no more to be accounted a Beauty, till she has killed her man, than the bullies think one a fine gentleman, till he has kill'd his.) (the OED). As noted by Ayto (2005), in the $18^{\text {th }}$ and $19^{\text {th }}$ centuries it was used with reference to a 'pimp' and nowadays, bully is employed as a synonym for a harasser of inferiors.

As to the phraseological productivity of the noun bully, the Dictionary of Phrase and Fable provides us with a note proving that in spite of the fact that nowadays the word is associated with menace, in the past it was frequently employed as a term of endearment, for example in Shakespeare's Midsummer Night's Dream ('O sweet bully Bottom') and Merry Wives of Windsor ('Bless thee, bully doctor').

\section{HONEY}

The semantic history of the lexical item honey dates back to Anglo-Saxon times. The word appeared in a number of modern European languages thanks to the Indo-European ancestors whose special word for it, based on the form melit-, has spread in other languages, such as French and Spanish miel, Italian miele and Welsh mel (Word Origins). Nevertheless, this form failed to persist in Germanic languages, which - in turn - developed other words for 'honey', for example German honig, Dutch honing, Swedish honung, and Danish honing, which all derive from the prehistoric West and North Germanic khunagom or khunanggom (Word Origins and the OED). Following Word Origins, this may originally have described the colour of honey, hence the connection with Greek knēkós 'pale yellow' and Sanskrit kāncana'golden'.

As the $O E D$ reports, the historically primary Anglo-Saxon sense of the word in question may be defined as 'a sweet viscid fluid, of various shades from nearly white to deep golden, being the nectar of flowers collected and worked up for food by certain insects, especially the honey-bee' and hence one may speak of an entrenchment link to the macrocategories SUBSTANCE and FOOD. Yet, taking into account the historically primary sense of the lexical item one must speak of the highlighting of the attributive value SWEET presupposed for the conceptual domain of TASTE. This sense of honey is evidenced in the following contexts extracted from the $O E D$ macrostructure:

825 Swoetran ofer hunie and biobread.

1422 Hote drynke makyd wyth Hoony.

1838 His body, immersed in honey, was carried home for a royal burial.

Following the $O E D$, in the middle of the $14^{\text {th }}$ century honey started to be employed with reference to people in the sense 'a term of endearment: sweet one, sweetheart, darling'. At first, this sense was used chiefly in Irish (in forms hinnie, hinny) Scottish and Northumbrian, but nowadays it is also common in both Northern America and Britain. This historically 
secondary sense of the noun is testified by means of the following quotations extracted from the OED:

1350 William seide, 'mi hony, mi hert al hol pou me makest'.

1712 Our affairs, Honey, are in a bad condition.

1968 'Honey' as an endearment, now rediscovered by southern Englishmen via Hollywood.

Undoubtedly, the process taking place here is that of foodsemy, hence we are justified to say that for the construal of the human-specific sense of honey we are dealing here with a shift from the conceptual macrocategory FOOD to the conceptual category ENDEARMENTS presented by means of the (SWEET) FOOD $\rightarrow$ ENDEARMENT pattern. Additionally, the rise of the novel sense of the word, namely 'sweetheart, darling' must be pictured in terms of activation of the conceptual element EPICENE presupposed for the attributive path of the conceptual domain of SEX. The transfer to the conceptual category HUMAN BEING may have been conditioned by the presence of a conceptual element SWEET, which is prominently relevant for the construal of both senses and hence provides the bridge for the shift.

Nowadays, apart from its historically primary sense, honey is frequently employed with reference to people we like (Hey honey, how you doing?) (http://www.urbandictionary.com/define.php?term=honey). The word also gave rise to a few compounds, such as honey-baby, honey-bun or honey-bunch which appeared at the beginning of the $20^{\text {th }}$ century and have been used as terms of endearment (e.g. I'm sorry, honeybunsorry. Guess I'm a little upset.) (Oxford Dictionary of Slang). Following Hendrickson (2008), several dictionaries of slang report that honey as a synonym for a lover is an Americanism coming from the 1880s. Interestingly enough, the same source elucidates further that in the British Museum's collection one may encounter a Greek gold betrothal ring from the $4^{\text {th }}$ century BC engraved inside with the word meli which in Greek means 'honey'.

\section{SUGAR}

Let us move on to the semantic history of another sweet word, namely sugar. The ultimate source of the noun is Sanskrit, where the substance was named with a lexical item sharkarā initially defining 'gravel, grit'. This form was acquired by Arabic as sukkar, which made its way into English via medieval Latin succarum, Italian zucchero, and Old French sukere (Word Origins). All the consulted lexicographic sources (the OED; Word and Phrase Origins) agree that the word was first documented as zukker at the close of the $13^{\text {th }}$ century (1299 Zuker Marrokes.) to define 'a sweet crystalline substance, white when pure, obtained from a great variety of plant juices, but chiefly from those of the sugar-cane and sugar-beet, and forming an important article of human food'. In cognitive terms, the historically primary sense of the word in question may be related to the macrocategories SUBSTANCES and FOOD. Moreover, one must speak of the highlighting of the attributive value SWEET presupposed for the conceptual domain of TASTE.

It was as late as in the $20^{\text {th }}$ century when the word started to be employed in humanspecific sense as a term of endearment. The noun was frequently used in combinations, such as sugar-babe, sugar-baby or sugar-pie. The following statements extracted from the macrostructure of the OED testify this human-specific sense of sugar: 
1930 Sugar-pie, common term of endearment.

1951 No, you don't, sugar, you don't go out with your cold.

1980 Okay, sugar, what are you looking for?

Similarly to honey, in the construal of the human-specific sense of sugar the process of foodsemy is at work here. Furthermore, one may speak of the diagnostic presence of the conceptual value EPICENE presupposed for the attributive path of the domain of SEX. The transfer to the conceptual macrocategory HUMAN BEING may have been conditioned by the presence of the conceptual value SWEET, which is prominently relevant for the construal of both the literal and figurative senses of sugar, and hence it provides the bridge for the shift of meaning.

\section{TART}

In line with its etymological roots, related to French (tarte) and Med. Latin (tarta), the original $15^{\text {th }}$-century English meaning of the word tart was 'name for various dishes consisting of a crust of baked pastry enclosing different ingredients' (1400 Tartes of Turky, taste whane peme lykys.) (the $O E D$ ). This historically primary sense of the word is related to the conceptual category FOOD. The word acquired a human-specific and - to be more precise - a female-specific sense as late as in the second half of the $19^{\text {th }}$ century when it was defined as an endearing term referring to females as seen from the following $O E D$ example:

1864 Tart, a term of approval applied by the London lower orders to a young woman for whom some affection is felt. The expression is not generally employed by the young men, unless the female is in 'her best'.

Cognitively speaking, the semantics of the historically secondary female-specific sense of tart may be accountable in terms of activating and highlighting the conceptual value FEMALE presupposed for the attributive path of the domain of SEX. Moreover, the mechanism of foodsemy is taking place here as well. Thus, we are dealing here with a semantic shift based on the pattern (SWEET) FOOD $6 \rightarrow$ ENDEARMENT.

However, twenty years later tart underwent the process of meaning pejoration and for unknown reasons took on its present sense of a female of immoral character or a prostitute, never to be employed endearingly again (Word and Phrase Origins). From that moment, the semantics of tart started to be associated with the conceptual category of FALLEN WOMAN. Obviously, the rise of this female-specific and negatively-loaded sense is accountable in terms of activation of such conceptual values as IMMORAL and PROMISCUOUS presupposed for the attributive path of the domain of MORALITY, which together with the FEMALE genderdetermining attributive value account for the rise of the novel sense. This sense of tart is attested by means of the following OED quotations:

\footnotetext{
6 Note that at first tarts were filled with meat, fish, cheese or fruit. However, nowadays they are only filled with fruit preserve or other sweet confection.
} 
1887 The paragraph referred to the young ladies in the chorus at the Avenue and spoke of them as 'tarts'. It was suggested on the part of the prosecution that the word 'tart' really meant a person of immoral character.

1979 I evolved a new way of dressing: five-inch high-heeled shoes, tight straight skirts, very very tight cheap sweaters, and masses of make-up. I looked just like a tart.

One may observe a marked tendency to make use of the words denoting sweet food (such as honey, sugar, pumpkin) as pet names for people. Mills (1995: 234-235) accounts for the reason why cooking terms - or, to be more precise, terms denoting cake - started to be employed with reference to females in the following words:

Like honeybun, sweetie-pie, cupcake and other terms employing a similar image, tart presumably derives from the notion of the supposed - and required - sweetness in a woman and perhaps from a male view that women are small, quick- to-consume, edible morsels.

In all likelihood, the process of metaphorisation is based on the fact that both females and tarts may be conceived of as being sweet. Hence, the conceptual element SWEET is shared by both the historically primary sense of the lexical item in question: 'a flat, usually small, piece of pastry, with no crust on the top (so distinguished from a pie), filled with fruit preserve or other sweet confection' and the historically secondary human-specific sense of tart: 'term of endearment'. In turn, the reason for the shift of meaning from the conceptual category ENDEARMENTS to FALLEN WOMAN is attributed to the fact that men tend to perceive women as sweet and easy to consume objects (Rusinek 2012).

\section{PUMPKIN}

The logic behind a number of terms of endearment is rather obvious. Take, for example, kitten, lamb, dove or honey, sugar, muffin which are connected with either the mechanisms of zoosemy or foodsemy. Nevertheless, the use of the noun pumpkin as a sweet word seems somewhat dubious and counterintuitive (http://english.stackexchange.com/questions/133015/ how-did-pumpkin-come-to-be-a-term-of-endearment). Not surprisingly, having scoured lexicographic sources (Word Origins; 500 Years of New Words; Word and Phrase Origins) one can hardly encounter any information concerning the affectionate definition of the word in question. It is fitting to add that internet sources record the affectionate sense of pumpkin. And thus, following one of them, the lexical item in question is a pet name referring to cute, adorable or sweet persons (especially females, children and babies) (http://www.urbandictionary.com/define.php?term=Pumpkin). It is elucidated further that pumpkin is employed as a synonym for 'a sweetheart', because of its pleasing nostalgic look (Aww look, that little pumpkin is dressed in a pumpkin costume for Trick or Treating!). Therefore, we may speak about a certain conceptual bridge between a pumpkin and a sweet person in the domain of APPEARANCE, because both a vegetable and a person share the same conceptual value, that is being PLEASANT.

As to the etymology of pumpkin, following the $O E D$, the noun was borrowed into English in the $17^{\text {th }}$ century (1647 He would come over to us, to helpe recruite our pumpkin blasted braines.). According to Word Origins, the lexical item comes from Greek pépōn employed with reference to a kind of melon, then it passed on to Latin as pepō. Old French took it over 
as pepon and in the $16^{\text {th }}$ century it entered the English lexicon and altered to pompion. The source elucidates further that a century later, the native diminutive suffix - kin was added to the word to form pumpkin.

In the first half of the $19^{\text {th }}$ century pumpkin started to be used figuratively in the humanspecific sense 'a stupid, self-important person' (1830 But I ain't a pumpkin, the Squire he knows that.) (the $O E D$ ). In turn, in the $20^{\text {th }}$ century the word underwent the process of amelioration of meaning and started to be employed as a term of endearment, especially for children. The OED lists the word as part of the American variety of English. The following $O E D$ quotations provide historical evidence of this sense of the word:

1942 Terms of endearment, pumpkins.

1980 Edible terms as endearments. Punkin.

1987 Listen, pumpkin, I thought you ought to know.

Cognitively speaking, the historically primary sense of pumpkin 'a large fruit' is related to the conceptual category FRUIT embedded in the macrocategory PLANTS. Clearly, the rise of the human-specific sense was based on the processes of foodsemy and plantosemy. Hence, within the plantosemic developmental path, we are dealing here with a mapping between the conceptual categories PLANT and HUMAN BEING, reflected in the rise of the sense given above (PLANT $\rightarrow$ HUMAN BEING pattern). Moreover, for the construal of the historically secondary human-specific sense of pumpkin 'a stupid and self-important person' one may speak about the conceptual values FOOLISH and CONCEITED presupposed for the attributive path of the domain of CHARACTER. Moreover, having scrutinizing this sense of the lexical item, the conceptual domain that is also central for the construal of its negativelyloaded sense is that of the domain of SEX for which the conceptual values EPICENE is activated. However, taking into account the positively-loaded sense of pumpkin we need to remember that the abovementioned values, namely FOOLISH and CONCEITED, become backgrounded. On the premise that pumpkin is - by and large - employed with reference to children, we may speak about highlighting of the conceptual value YOUNG presupposed for the domain of AGE.

\section{SWEETHEART}

In turn, some words from the very beginning of their existence until now have been employed as endearments. The history of the compound sweetheart provided by the OED says that the word appeared in English at the close of $13^{\text {th }}$ century and was from the very start applied in the sense 'darling'. It is fitting to add that, as noted in the Oxford Dictionary of Slang, the word was employed chiefly in the vocative and apart from its endearing sense, in specific context, it may be used ironically, threateningly or contemptuously as well. The historical primary sense of the compound is evidenced by the following OED quotations:

1290 Alas pat ich scholde a-bide Pat mi child, mi swete heorte, swych cas schal bi-tide.

1679 My Husband called to me, prithee, sweetheart, what hast thou got for my Supper?

1977 Try harder, sweetheart, or I'll plug you in the guts. 
Following the Dictionary of Phrase and Fable, sweetheart is a synonym for a lover of either sex, hence one may speak of an entrenchment link to the conceptual domain of SEX for which the evaluatively neutral conceptual element EPICENE is activated. The lexical item is frequently employed in the contemporary world, for example in Frank Sinatra's song 'Two sweethearts and the summer wind'. Moreover, one may easily come across this word in a number of novels, such as Toni Morrison's Jazz: The city sky was hidden . . otherwise it could show me stars cut from the lame gowns of chorus girls, or mirrored in the eyes of sweethearts furry and happy under the pressure of a deep, touchable sky (Metaphors Dictionary).

\section{JOY}

Let us move on to the semantic history of the simple word joy. All the consulted lexicographic sources (the OED; Word Origins; A Short Etymological Dictionary of Modern English) agree that the noun comes from Latin gauderre 'rejoice'. According to the OED, in the history of English, the word appeared in the first half of the $13^{\text {th }}$ century and was defined as 'a vivid emotion of pleasure arising from a sense of well-being or satisfaction; the feeling or state of being highly pleased or delighted; exultation of spirit; gladness, delight'. In terms of the cognitive mechanisms put to use here, the word is part and parcel of the conceptual category HAPPINESS embedded in the macrocategory (POSITIVE) EMOTIONS. This historically primary sense of joy is evidenced by the following selected material extracted from the $O E D$ context:

1225 Auh efter pe spreoue, on ende,--peonne is pe muchele ioie.

1867 It is a comely fashion to be glad-Joy is the grace we say to God.

At the close of the $16^{\text {th }}$ century joy acquired human-specific sense and began to be employed as an endearment term synonymous for 'a sweetheart, child, or a darling' (the $O E D)$. The $O E D$ illustrates the historical presence of this sense of joy in the history of English by means of the following quotations:

1590 While I kisse thy faire large eares, my gentle ioy.

1789 Pretty joy! Sweet joy but two days old

1876 'My bonny joy!' my pretty dear.

Cognitively speaking, we are dealing here with an interesting and rare semantic shift based on the pattern (POSITIVE) EMOTIONS $\rightarrow$ ENDEARMENTS. In all likelihood, we can speak about a certain conceptual bridge between joy 'a vivid emotion of pleasure' and 'sweetheart, honey' in the domain of EMOTIONS. To be truly happy people need to be with someone who makes them happy; hence the pet name joy is used with reference to beloved people.

\section{PET}

Historically speaking, following the $O E D$, the origin of the word pet is unknown. The first documented human-specific use of the noun in English comes from the beginning of the $16^{\text {th }}$ century when it was applied as an endearment term for an indulged (and spoiled) child (Sherk 
2004). Evidently, the conceptual value that is foregrounded in the case at hand is that of YOUNG, as well as the gender-general element EPICENE, presupposed for the attributive paths of the conceptual domains of AGE and SEX, respectively. Moreover, one may also speak of the activation of such evaluatively coloured conceptual elements as INDULGED or SPOILED, presupposed for the attributive path of the conceptual domain of BEHAVIOUR. This human-specific sense of the word may be evidenced by means of the following OED historical contexts of use that go as far back as the beginning of the $16^{\text {th }}$ century:

1508 Herretyk, lunatyk, purspyk, carlingis pet.

1788 Pet, a child spoilt by improper indulgence.

Later, in the first half of the $16^{\text {th }}$ century, the word extended its meaning and started to be defined as 'any animal that is domesticated or tamed and kept as a favourite, or treated with indulgence and fondness'. The lexical item was particularly employed with reference to a lamb (or kid) 'taken into the house, and brought up by hand, a cade lamb' (the $O E D$ ). In this case, the semantics of the historically secondary meaning of pet belongs to the conceptual macrocategory ANIMALS. This animal-specific sense is evidenced by means of the following quotations extracted from the $O E D$ :

1539 Item, to Thomas Melvillis Wiffe, in Falkland, at pe Kingis command, for keping of certane Pettis, and nurising of pe samyn.

1830 The animal is cleanly in its habits, and is reared in the houses rather as a pet.

In turn, as given in the $O E D$, in 1755 pet extended its human-specific sense and began to be employed with reference to adults who are indulged, fondled, or treated with special kindness or favour. This sense of the simple word is evidenced by the following OED quotations:

1755 Peat, a little fondling; a darling; a dear play-thing. It is now commonly called pet.

$1825 \mathrm{Pet}$, a fond designation for a female favourite.

1976 Be a pet and fetch me a Tom Collins.

However, it was as late as at the close of the $19^{\text {th }}$ century when the above-mentioned semantics of pet developed and the noun started to be used as a term of endearment or familiar vocative. Following the Oxford Dictionary of Slang, the term is employed mostly by women, or by men to women. Moreover, pet is common in the north-east of England (Newcastle especially). See the TV series 'Auf Wiedersehen, Pet' about builders, some from Newcastle, working in Germany. In terms of the cognitive mechanisms put to use here, the construal of the human-specific sense of the word necessitates postulating activation of the conceptual value EPICENE presupposed for the attributive path of the conceptual domain of SEX. Moreover, it can also be accountable for in terms of an entrenchment link to the domain of AGE, for which the conceptual element ADULT is activated. This human-specific sense of the noun may be illustrated with selected literary contexts drawn from the $O E D$ files:

1849 Do you know, pet, it seems almost a dream to me that we have been married.

1939 There is a parcel I want to send up to Thomasine Fair. Will you run up with it this afternoon, pet?

1977 Sounds like just the job for you, pet, eh? 


\section{MOPSY}

In all likelihood, the word is an amelioration of the noun mop 'a fool'. The OED reports that the ending -sy is attached to words to form terms of endearment, as in babsy or ducksy. Mopsy employed as a sense of endearment, and defined in the OED as 'a pretty child; a darling, a sweetheart', was first recorded in the history of English in the second half of the $16^{\text {th }}$ century. This historically primary human-specific sense of the word may be confirmed with the following illustrative contexts extracted from the OED database:

1582 Thee mopsy her phantasye lurcheth.

1583 Borrowed for the most parte of their pretie Mopsies \& loouing Besses.

1706 These mix'd with Brewers, and their Mopsies.

The lexical item in question was frequently employed with reference to a child and - by and large - young females (along with mops and moppet). However, over time it started to refer to any women, especially ones of rather small stature. As reported by Crystal (2014), this sense of the word continued to be widespread in northern and eastern dialects of England. It is worth noting that even nowadays mopsy may be encountered in literature; however, it reflects a rather pejorative sense 'a slatternly, untidy woman' which developed at the very beginning of the $18^{\text {th }}$ century (the OED). The OED offers the following quotations in support of this negatively-loaded sense of the word:

1700 Crew, Mopsie, a Dowdy, or Homely Woman.

1958 Poor Swann's pain and frustration are a simpler matter, Odette de Crécy being the most commonplace of lying mopsies and a born torturer of the sensitive.

Cognitively speaking, to account for the historically primary sense of mopsy 'a pretty child; a darling, a sweetheart', one may speak about an entrenchment link to the attributive path of the domains of SEX, AGE and APPEARANCE, for which the conceptual values EPICENE, YOUNG and PRETTY are foregrounded respectively. In turn, the rise of the historically secondary sense 'a slatternly, untidy woman' is accountable for in terms of the activation of such a negatively-loaded conceptual value as DIRTY presupposed for the attributive path of the domain of CHARACTER AND BEHAVIOUR. Moreover, we may speak about the prominence of the FEMALE gender-determining attributive element to account for the rise of the novel sense. Having considered the historical development of lexical items which represent objects belonging to the conceptual category FEMALE HUMAN BEING, we may come to the conclusion that - in the vast majority of cases - we encounter the process of the evaluative downfall of such terms. Women-terms, even the most innocent ones, may in the course of time acquire new negatively-loaded senses and become offensive; and it is mainly due to the fact that - as stressed by Bosmajian (1974: 90) - the language of sexism relegated women to the status of children, servants, and idiots, to being the 'second sex' and to virtual invisibility. 


\section{Conclusions}

Given that endearments originate from our individual, linguistic and national creativity, it is not an easy task to compile a comprehensive dictionary of such terms. Suffice it to say that apart from expressions deeply ingrained in a given culture, this domain evolves very quickly; many terms fall into oblivion and new ones constantly extend our lexicon. Furthermore, a number of endearments undergo the processes of meaning amelioration (see mopsy) or pejoration (see bully, tart). Not infrequently, we deal with a situation in which positively- or neutrally-loaded lexical items naming objects belonging to the conceptual category ENDEARMENTS acquire new, negatively-loaded senses and sometimes may even become offensive. The semantic developments of bully or tart prove that the historically primary positively-loaded sense of a word may fall into oblivion and be replaced with a new one which by no means resembles its initial sense. Degradation of meaning is frequent when analyzing terms which used to be sweet words (for example bully, tart). Furthermore, due to the fact that ENDEARMENTS are associated with POSITIVE EMOTIONS, especially LOVE, a group of pet names started to be used with reference to the domain of SEXUALITY, and - to be more precise - FALLEN WOMEN, for example tart which today is known as a promiscuous woman.

It should be noted that there is no scale which would indicate which term is the most or the least 'endearing'. Provided that the speaker's intention is to evoke positive feelings, sweet words seem to be rather equal. ${ }^{7}$ Interestingly, English pet names seem to be neither poetic nor exalted; and apart from a few cases they lack humour and creativity. Obviously, such terms usually refer to notions associated with something positive, for example tasty sweet food (honey, sugar, tart), nevertheless one may encounter quite a few terms which might sound offensive, although we can take it for granted that they are endearments (pumpkin, bastard, monster, freak) (The Concise New Partridge Dictionary of Slang and Unconventional English).

Not surprisingly, taste and animal terms seem to be two dominant motifs in the creation of new endearments, hence we may speak about two main patterns, namely (SWEET) FOOD $\rightarrow$ ENDEARMENT and ANIMAL $\rightarrow$ ENDEARMENT. However, as noted by Crystal (2014), the lack of the domain FLOWERS seems to be most surprising when analyzing endearments. Apart from daisy, which is an obscure term of admiration ${ }^{8}$ one may come across nonce usages of daffodil, tulip and other flower-terms, but their frequency is not sufficient to be documented by lexicographers. The author elucidates further that among the endearments, the lexical items naming objects belonging to the domain APPEARANCE are few and far between. One may encounter only a handful of terms connected with the domain COLOUR (e.g. golpol, pinkany) ${ }^{9}$, an allusion to the eyes (e.g. nykin) ${ }^{10}$ and a handful of words relating to

\footnotetext{
7 We need to remember that in particular contexts endearments may be used ironically or contemptuously (see the development of sweetheart).

8 The $O E D$ records only two cases of its existence:

1485 A dere dewchesse, my daysyys Iee! 1605 Adeu, O desie of delyt.

9 The OED attests only a single quotation from the $16^{\text {th }}$ century $(1568 \mathrm{Giij}$, It is your deinty dearlyng, your princkoxe, your golpoll.). The form golpol comes from gold-pol. In turn, the existence of pinkany defined as
} 
the domain SIZE (e.g. $p u g)^{11}$. The domain BEHAVIOUR is likewise missing, as Crystal (2014) notes only one pet name (wanton) $)^{12}$ belonging to this domain.

Undoubtedly, the phenomenon of endearments has not yet been fully examined in English. A researcher comes across a number of obstacles when delving into this constantly changing conceptual domain, such as the shortage of sources. The existence of such terms is important from linguistic and social viewpoints, as they clearly demonstrate both language changes and relations between people. Examining pet names from a given country would tell us a lot about not only a language, but also a culture.

\section{References}

Ayto, J. 1998. Oxford dictionary of slang. Oxford: Oxford University Press.

Ayto, J. 2005. Word origins. London: A\&C Black.

Benbow, T.J., J. A. Simpson, and E.S.C Weiner. 1984-1989. The Oxford English dictionary. Oxford: Oxford University Press (2002 compact edition).

Bosmajian, H.A. 1979. The language of oppression. Washington, D.C.: Public Affairs Press.

Busse, U. 2002. Linguistic variation in the Shakespeare corpus. 163-173. Philadelphia: John Benjamins.

Cobham Brewer, E. 2003. Dictionary of phrase and fable. Blackmask Online. http://www46.homepage.villanova.edu/michael.foight/brewersdictphrasefable.pdf

Crystal, D. 2014. Words in time and place: Exploring language through the historical thesaurus of the Oxford English Dictionary. Oxford: Oxford University Press.

Dalzell, T., and V. Terry. 2008. The concise new partridge dictionary of slang and unconventional English. London/New York: Routledge.

Hendrickson, R. 2008. The facts on file encyclopedia of word and phrase origins. Fourth Edition. New York: Facts on File.

Kochman-Haładyj, B. 2007. Low wenches and slatternly queans: On derogation of women terms Studia Anglica Resoviensia 4: 206-228.

Lakoff, G. 1987. Women, fire and dangerous things. Chicago/ London: The University of Chicago Press.

Langacker, R. W. 1987. Foundations of Cognitive Grammar. Stanford: Stanford University Press.

Lewin, E., and A. E. Lewin. 1988. The Random house thesaurus of slang. New York: Random House.

Liberman, A. 2008. An analytic dictionary of English etymology. Minneapolis/ London: University of Minnesota Press.

'darling, pet' was even shorter, as the word was in use for only about twenty years. It appeared at the close of the $16^{\text {th }}$ century (1599 The other was Hero, she was a pretty pinckany and Venus priest.) and vanished soon afterwards (1622 That pink-an-eye jack-an-apes boy, her page.).

10 The OED provides us with two quotations taken from the same source testifying the existence of this endearment (1639 I hope my dearest Jewel is not going to leave me. Are you Nykin? Fondle wife, Go naughty. Nykin, you don't love me.)

11 According to the OED, pug employed as a term of endearment entered the English vocabulary stock in the $16^{\text {th }}$ century (1566 If in a couche, a fyne fleesde lambe a kinge shoulde cause to ryde, And geve it rayments neate and gay. And call it pugges and prety peate), but soon fell into oblivion, as the last quotation recorded in the macrostructure of the OED comes from the beginning of the $17^{\text {th }}$ century (1611 M'amie, Ma belle m'amie, my prettie Pug).

12 The $O E D$ claims that the existence this human-specific sense of wanton 'a person, esp. a child of playful, roguish or sportive conduct (sometimes used as a term of endearment)' was short-lived. Consider the following $O E D$-recorded contexts of use:

1589 Wepe not my wanton! smile vpon my knee!

1616 Peace my wantons. 
Mills, J. 1989. Womanwords. London: Longman.

Nartey, M. and J.B.A. Afful. 2013. Hello sweet pie: A sociolinguistic analysis of terms of endearment in a Ghanaian University. The International Journal of Social Sciences, Vol. 17 No. 1. Tijoss.

Partridge, E. 2006. A short etymological dictionary of Modern English. London/New York: Routledge.

Rayevska, N. M. 1979. English lexicology. Kiev: Kiev: Vysca Skola Publishers.

Rusinek, M. 2012. On the contiguity of the semantic fields 'CAKES' and 'HUMAN BEING': The case of tart. Annals of Arts 60,5/112: 101-112 (on www.ceeol.com).

Schmid, H.J. 2010. Entrenchment, salience, and basic levels. In D. Geeraerts, and H. Cuyckens (eds.), The Oxford handbook of Cognitive Linguistics, 117-138. Oxford: Oxford University Press.

Sherk, B. 2004. 500 Years of new words. Toronto: The Dundurn Group.

Sommer, E., and D. Weiss. 2001. Metaphors dictionary. Detroit: Visible Ink.

Taylor, J.R. 1995. Linguistic categorization. Oxford: Oxford University Press.

Weekley, E.1924. A concise etymological dictionary of Modern English. New York: E.P. Dutton and Company.

http://www.yaelf.com/toe.shtml

http://blog.maart.com/en/content/language-love-international-and-polish-terms-endearment

http://english.stackexchange.com/questions/133015/how-did-pumpkin-come-to-be-a-term-of-endearment

http://www.urbandictionary.com/define.php?term=honey 